\title{
A new method to identify the foot of continental slope based on an integrated profile analysis
}

\author{
Ziyin $\mathrm{Wu}^{1,2} \cdot$ Jiabiao $\mathrm{Li}^{1,2} \cdot$ Shoujun $\mathrm{Li}^{1,2} \cdot$ Jihong Shang ${ }^{1,2} \cdot$ Xiaobin Jin ${ }^{1,2}$
}

Received: 29 December 2015/Accepted: 17 May 2016/Published online: 3 June 2016

(c) The Author(s) 2016. This article is published with open access at Springerlink.com

\begin{abstract}
A new method is proposed to identify automatically the foot of the continental slope (FOS) based on the integrated analysis of topographic profiles. Based on the extremum points of the second derivative and the DouglasPeucker algorithm, it simplifies the topographic profiles, then calculates the second derivative of the original profiles and the D-P profiles. Seven steps are proposed to simplify the original profiles. Meanwhile, multiple identification methods are proposed to determine the FOS points, including gradient, water depth and second derivative values of data points, as well as the concave and convex, continuity and segmentation of the topographic profiles. This method can comprehensively and intelligently analyze the topographic profiles and their derived slopes, second derivatives and D-P profiles, based on which, it is capable to analyze the essential properties of every single data point in the profile. Furthermore, it is proposed to remove the concave points of the curve and in addition, to implement six FOS judgment criteria.
\end{abstract}

Keywords FOS - Quadratic fitting - Second derivative · Automatic identification

Ziyin Wu

ziyinwu@163.com

1 Key Lab of Submarine Geosciences, State Oceanic Administration, Hangzhou, China

2 Second Institute of Oceanography, State Oceanic Administration, Hangzhou, China

\section{Introduction}

The demarcation of the continental shelf beyond 200 nautical miles is one of the most significant marine scientific problems. On December 20th, 2001, Russia submitted its delimitation scheme to the Commission on the Limits of the Continental Shelf (CLCS) through the Secretary-General of the United Nations (UN 2013). This is the first scheme submitted by a coastal state after the United Nations Convention on the Law of the Sea (UNCLOS) came into effect in 1994. As a milestone, it opened a new chapter that coastal states worldwide began to submit their delimitation applications.

Compiling a complete demarcation scheme requires a systematic approach and various evidences, including details of the topography, the relevant scientific evidences and texts pursuant to Article 76 of UNCLOS, and the technical requirements regarding delimitation as set by CLCS (UN 1983, 1993, 1999). The key evidence is a series of demarcation lines, including the foot of the continental slope (FOS) line, the formula line (FOS $+60 \mathrm{~m}$ line and $1 \%$ sediment thickness line), the limit line ( $350 \mathrm{~m}$ line and $2500 \mathrm{~m}+100 \mathrm{~m}$ line), and the external boundary. Of these, the FOS line is the most important one, because it is the starting line to determine the limits of the continental shelf and affects directly the accuracy of the formula line and, ultimately, the external boundary coordinates and the delineated area.

FOS is an essential element for the delimitation scheme submission required by CLCS (Jun 2014; Kaye 2015; Wu et al. 2014), and is the most important research content in the deliberation of the delimitation scheme. Thus, the accurate location of the FOS points directly results in the ultimate location of the external limits deliberated by CLCS. Although there is some published 
literature relating to the study of the FOS (Alcock et al. 2003; Collier et al. 2002; Magnússon 2014; Reichert 2009; Verhoef et al., 2011), most of it focusses on the law of the sea (Antunes and Pimentel 2003; Carleton 2006; Gao 2012; Jakobsson et al. 2003; Qiu et al. 2013). Until now, only a few studies directly address the FOS recognition algorithm, of which seldom are published in journals, most are conference papers or reports. Peter et al. (2000) discussed in detail the technical method, data and processes, etc., necessary to determine the outer limit of the continental shelf beyond 200 nautical miles. Vaníček et al. (1994) and Ou and Vaníček (1996) proposed an automatic identification method of the FOS by converting the water depth surface into a maximum curvature surface (MCS), and then assuming the FOS line corresponds to the carinate shape of the MCS. However, the same MCS possibly corresponds to different terrain, so the method of MCS is only fitting a simple continental shelf. To overcome the ETOPO5 data error and noise problems, Bennet (1998) suggested a method that shows the FOS line on a map based on a surface of directed gradient (SDG) algorithm, which is essentially a method of spline smoothing and the second derivative. However, he did not provide a specific FOS recognition algorithm. $\mathrm{Li}$ and Dehler (2012) tried to identify the FOS based on a singular spectrum analysis (SSA). A fractal terrain algorithm processed noisy topographic data and the data were filtered by SSA. In general, the previous studies focused more on data filtering, but less on the specific method for FOS identification.

CARIS LOTS and Geocap are common softwares for the delimitation of the continental shelf, both of which have the FOS recognition function. However, the specific FOS recognition algorithms of CARIS LOTS have not beed published. Mugaas (2013) introduced the functionality of Geocap and its unique average gradient method, and compared the impact of different gradient calculation methods on the FOS identification. Given that the software applies multiple methods for filtering the original topographic profile, it may modify the essential characteristics of the original profile and finally affect the precise location of the FOS.

This paper proposes a new approach to FOS identification by integrating various information/data. This method can comprehensively and intelligently analyze the topographic profile and its derived slope, second derivative and D-P profile, based on which, it is capable to analyze the essential properties of every single data point in the profile. Furthermore, it is proposed to eliminate concave points in the profile and in addition, to implement six FOS judgment criteria.

\section{Background}

\section{Relationship between the continental shelf and the foot of the continental shelf}

According to Article 76 of UNCLOS of 1982, which also forms the basis for the worldwide coastal states to claim their continental shelves beyond 200 nautical miles, the coastal states should submit information on the limits of the continental shelf beyond 200 nautical miles from the baselines, from which the breadth of the territorial sea is measured to the CLCS, and then establish the outer limits of their continental shelves based on the recommendations made by CLCS.

Continental margin comprises continental shelf, continental slope and continental rise (Fig. 1a), where the concept of the continental shelf here differs from, but is only a part of the one defined in UNCLOS. The continental margin can be divided into three types (Peter et al. 2000): (1) the Atlantic type; (2) the Pacific type; and (3) the transformation type. From the research on the changes from continental crust to oceanic crust, and natural extension boundary markers of coastal states, Hedberg (1976) suggested that "the outer edge of the continental margin should be best defined as the external boundary of the topographical continent, which is usually accurately explained as the bottom of the continental slope".

The determination of the outer limits of the continental shelf beyond 200 nautical miles, in Article 76 of UNCLOS, mainly refers to the Atlantic-type continental margin, which shows clear submarine morphologic feature. A complete Atlantic-type continental margin comprises continental shelf, continental slope, continental rise, and oceanic basin, where the FOS point is located between the lower part of the continental slope and the continental rise (Fig. 1(a)). Comparatively, a Pacific-type continental margin is extremely complicated owing to the effects of plate convergence and subduction compression, and consists of multiple geomorphological units, including continental shelf, back-arc basin, island arc, fore-arc basin, oceanic trench, and abyssal plain from the continent to the ocean. Thus, the FOS point can be found on both sides of the back-arc basin and along the oceanic trench (Fig. 1(b)).

\section{Determining the continental slope base region according to topography}

In the absence of evidences, the FOS shall be determined as the point of maximum change of gradient at the continental slope base (UN 1993, 1999). The determination of the FOS can be divided into two steps: (1) determining the 
Fig. 1 Continental margin model and the theoretical location of the foot of the continental slope. (a Atlantictype continental margin; b Pacific-type continental margin; FOS the foot of the continental slope)
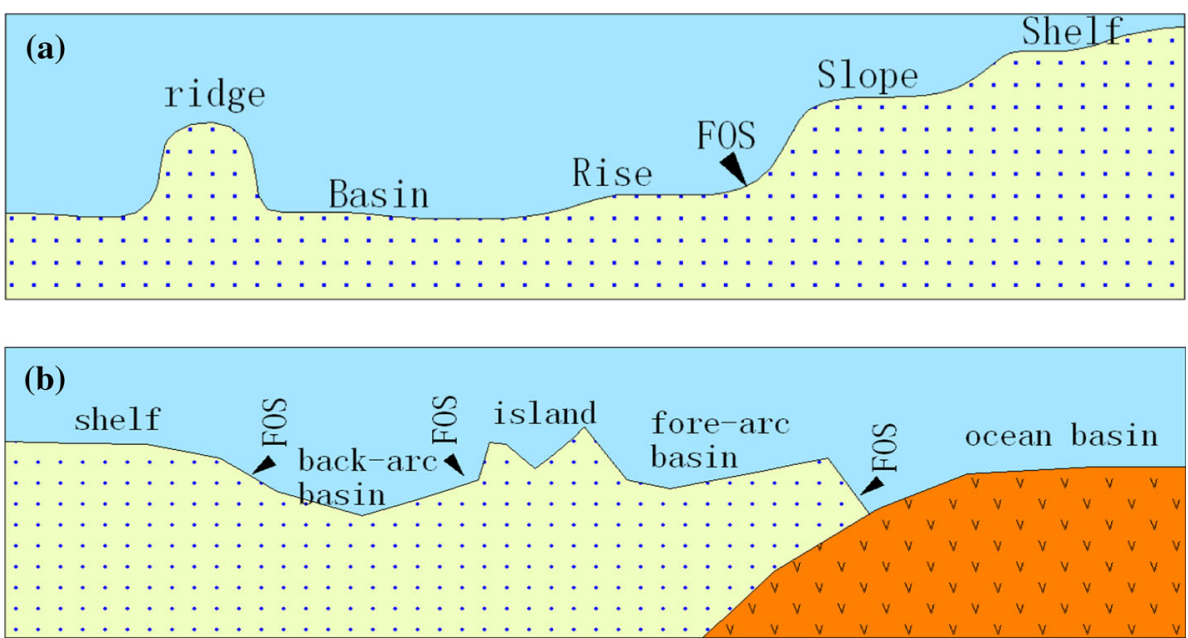

region defined as the base of the continental slope; and (2) determining the location of the point with maximum change in gradient at the base of the continental slope.

As submarine topography is complicated on a continental slope, the base region of the continental slope must be determined before determining the FOS points; i.e., the base of the continental slope is the area that the FOS point is likely to locate. The FOS point is located along the continent-ocean boundary (COB), whereas the determination of the continental slope base region requires multiple evidences, of which, submarine topography is one of the most important. Thus, the region that exhibits the typical topographic feature of "continental shelf-continental slope -oceanic basin" is supposed to be the appropriate region to determine the FOS points. Generally, the continental slope base region can be determined intuitively based on submarine topography (Hedberg 1976). It can be determined by an integrated analysis of water depth, topography, gradient, and second derivative profile.

\section{Automatic identification of the FOS based on an integrated analysis of topography, slope and second derivative profiles (TSDPIA)}

\section{Douglas-Peucker algorithm and its improvement}

The Douglas-Peucker algorithm (abbreviated as D-P algorithm) proposed by Douglas and Thomas (1973) is an algorithm for curve simplification, which can significantly reduce the number of redundant points, but retain the basic characteristics of a curve. Generally, recursive functions are applied in this algorithm. However, it has been found unnecessary in the program implementation process, when a designed data structure can store all the information before and after the query points in the curve. Another point should be noted is that the value of the initial distance deviation (D) will affect the output of the curve simplification. That is, a larger value will remove too much details, whereas a smaller value will result in a poor simplification effect. The program can automatically adjust the $\mathrm{D}$ value, in order to produce a quick but good simplification of the curve. An integral algorithm is the prominent advantage of the D-P algorithm which can preserve the points of maximum change in the curve; i.e., the shape of the simplified curve remains unchanged, which meets the requirement of the FOS identification. To identify a FOS point is to find a water depth data point with maximum change in gradient, which is also an extremum point of the second derivative in a topographic profile, located at the turning point from the continental slope to the oceanic basin.

\section{Technical method}

The method to determine the FOS needs to be accurate, quantitative and verifiable. The present method builds a series of topographic profiles vertical to the strike direction of the continental slope, and then determines the FOS points according to the changes in the submarine topographic profile. However, it is difficult to make the determination solely on the basis of the topographic profile, MCS or SDG; hence, other sources of information are needed to perform an integrated analysis of the location of the FOS points. The proposed method is therefore called TSDPIA.

The FOS, defined as the topographic point with maximum change in gradient (UN 1993, 1999), corresponds to the extremum point of the second derivative, rather than the zero-value point of the gradient profile; thus, the FOS is often not the extremum point in the topographic profile. Moreover, the comparison result indicates that the extremum point of the second derivative is always near the extremum point of the topographic profile, but normally they do not overlap. The topographic profile where the FOS 
point located presents a convex feature (longitudinal axis is displayed in the direction of increasing water depth). Therefore, the point with an extreme and positive second derivative value is a potential FOS point. Owing to the influence of the small-scale topography, a topographic profile might have several second derivative extremum points, and thus, the original topographic profile must be simplified.

A typical topographic profile of the continental margin comprises three sections (Fig. 2): a flat and shallow-waterdepth continental shelf, a steep and sharp-change-waterdepth continental slope, and a flat and deep-water-depth oceanic basin. The FOS is located at the turning point from the continental slope to the oceanic basin, where the water depth is relatively deep, while the gradient is relatively greater towards the continental slope and smaller towards the oceanic basin, respectively. For an original topographic profile, as influenced by small-scale local topography, there could be several points consistent with the conditions mentioned above. Therefore, the original profile should be simplified to eliminate the interference of local topography.

Filtering can smooth the original topographic profile and make it easier to identify the FOS. However, it has a potential defect that the basic characteristics of the original topographic profile might be changed. In contrast, by using extremum points and the quadratic fitting of the D-P algorithm, not only the original topographic profile can be simplified, but also the features of the original profile can be retained. The D-P algorithm has the significant advantage of retaining the most basic features of a curve, while it is difficult to determine directly the location of the FOS simply by fitting the original topographic profile. The point selected by the D-P algorithm might not be the extremum point of the second derivative of the curve, i.e., the D-P algorithm might remove the extremum point of the second derivative during the filtering. Therefore, prior to the D-P algorithm fitting, we should fit the original profile based on the extremum point of the second derivative, and then apply the D-P algorithm to perform the quadratic fitting based on the extremum point profile. Thus, it can be ensured that each point obtained is an extremum point of the second derivative, which can avoid a false FOS point.

By calculating the second derivative of the D-P topographic profile, a new gradient profile and a second derivative profile can be obtained. The profile following two processes of simplification retains only the most basic characteristics of the curve, without interference from small-scale local topography. Hence, we can analyze the features of each point in the D-P profile, including the water depth, the gradient, the second derivative, the concave-convex characteristic, and the correlation (continuity) between the point and its neighboring points on the upper slope, lower slope and the water depth, and then judge whether the topographic change corresponds to the typical characteristics (segmentation) of the turning point from the continental slope to the oceanic basin. With these parameters, we can determine accurately the location of the FOS points in the curve (Fig. 2).

\section{Technical process}

For a given grid digital depth model (DDM), the FOS point can be identified automatically following seven steps (including grid cutting, first derivation, initial topographic simplification, second topographic simplification, second derivation, concave terrain elimination, and comprehensive judgment) and six criteria (Fig. 3), which are discussed below.

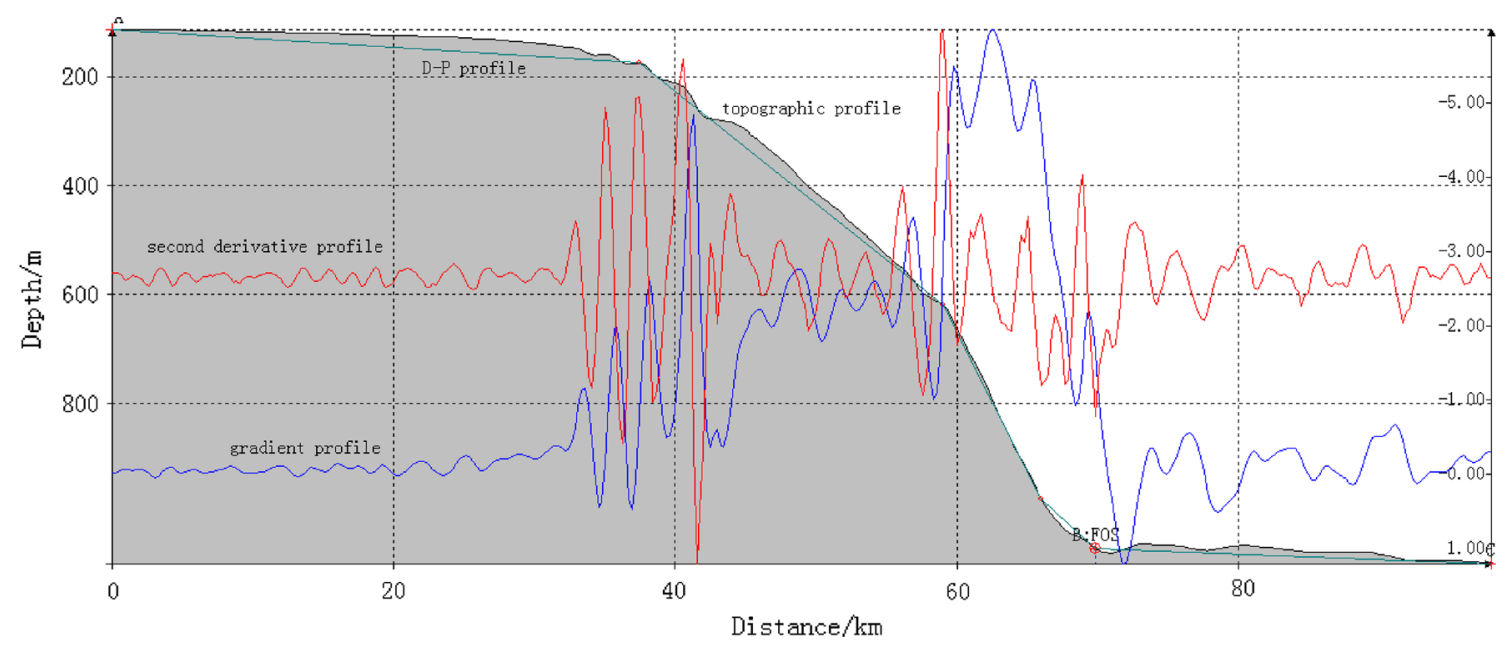

Fig. 2 Comprehensive profile to determine FOS 


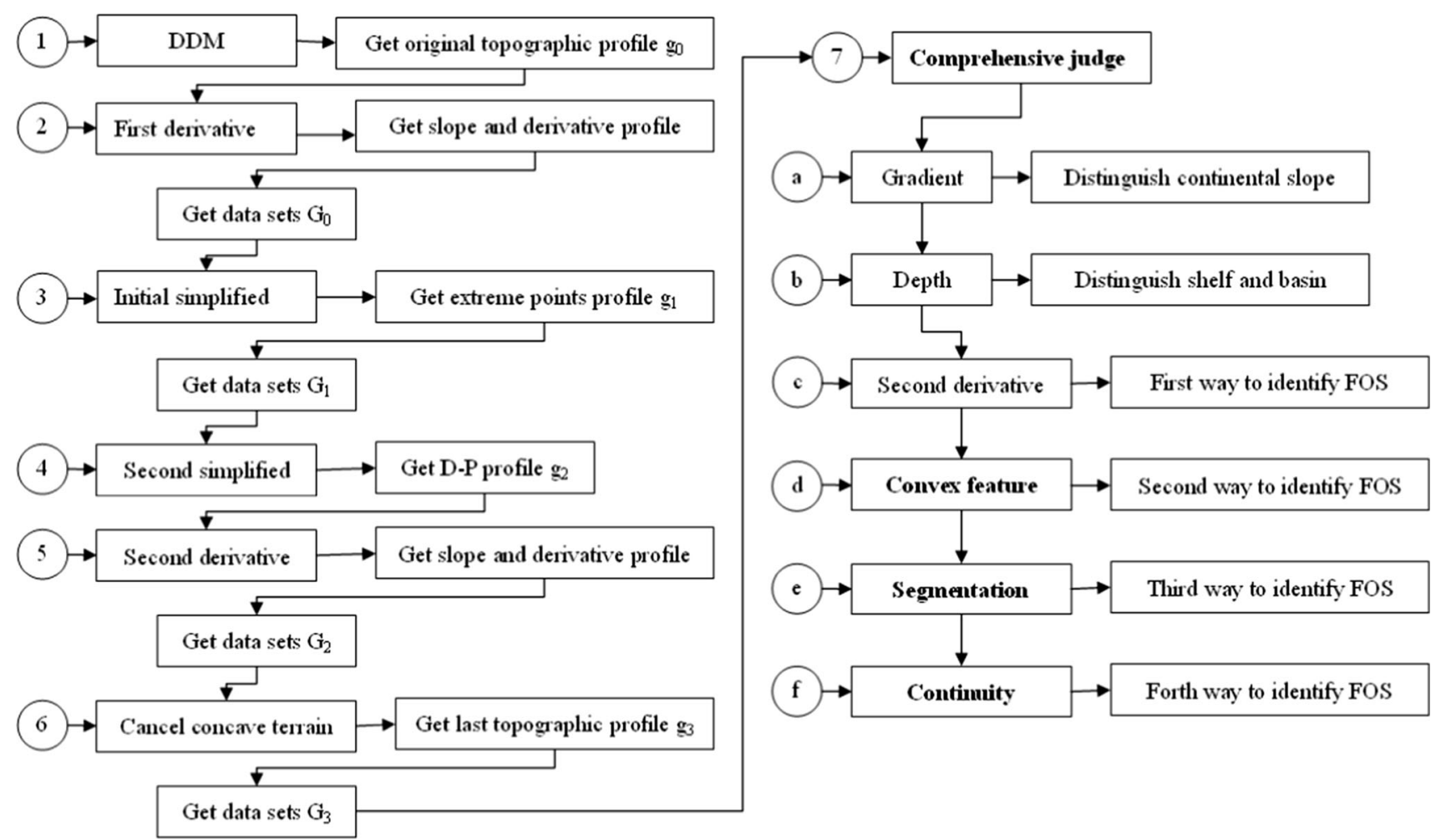

Fig. 3 Technical process of FOS identification

\section{Step 1: Grid cutting}

An original topographic profile $\mathrm{g}_{0}$ is obtained by using a series of straight lines to cut the digital depth model and then, running the intersection calculation. The topographic profile obtained should match the " continental shelf continental slope-oceanic basin” feature (Figs. 3, 4(a)).

\section{Step 2: First derivation}

A slope gradient profile and a second derivative profile are obtained by computing the derivative of the topographic profile curve. Then, the distance, the topography, the gradient, and the second derivative of the profile together form the data set $\mathrm{G}_{0}$ (Figs. 3, 4(a)).

\section{Step 3: Initial topographic simplification}

Only the extremum points of the second derivative profile are retained, the coordinates of which, together with the water depth data points, forming a new simplified topographic profile $g_{1}$ and a new data set $G_{1}$. Compared with the original topographic profile, it can be found that only a water depth data point that is in accordance with the characteristic of a second derivative extremum point can be retained (Figs. 3, 4(b)).
Step 4: Second topographic simplification

Applying the D-P algorithm to process the initially simplified topographic profile $\mathrm{g}_{1}$, we can obtain a new data set $\mathrm{G}_{2}$, which meets our requirements and forms a new topographic profile $\mathrm{g}_{2}$. The secondly simplified topographic profile $\mathrm{g}_{2}$ retains only a small portion of data points that meet the requirements (Figs. 3, 4(c)).

\section{Step 5: Second derivation}

By calculating the derivative of the topographic profile $\mathrm{g}_{2}$ (the second derivative), a new gradient profile and a second derivative profile are formed (Fig. 3).

\section{Step 6: Concave terrain elimination}

Utilizing the second loop to check through all the data points in the topographic profile $\mathrm{g}_{2}$, the points with concave features can be eliminated to form a new data set $\mathrm{G}_{3}$. From this, a new topographic profile $\mathrm{g}_{3}$, a new gradient profile and a second derivative profile are formed (Figs. 3, 4(d)).

\section{Step 7: Comprehensive judgment}

Through steps (1) to (6), a simplified integrated profile is obtained. After two processes of simplification and 

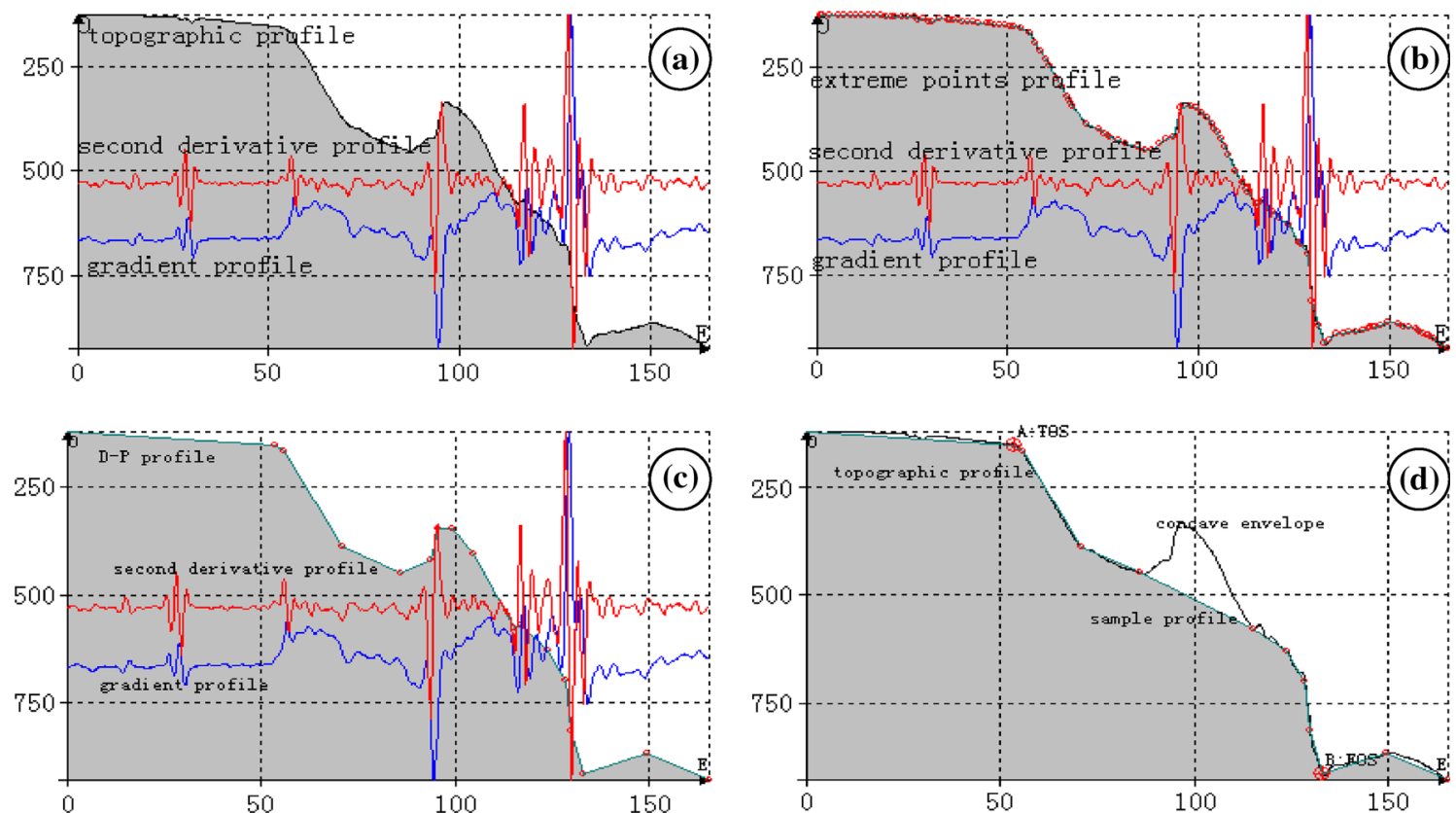

Fig. 4 Typical topographic profile and the process of FOS identification (a the original topographic profile; $\mathbf{b}$ the extremum-point profile; $\mathbf{c}$ the $\mathrm{D}-\mathrm{P}$ profile; $\mathbf{d}$ the concave-eliminated profile and the identified FOS)

concave elimination, the topographic profile is simplified considerably, wherein the continental shelf and the oceanic basin present flat topography feature, while the continental slope shows a singular gradient. Then, we can examine the topographic profile $\mathrm{g}_{3}$ to identify the FOS points according to the following six criteria (Fig. 3).

\section{Criteria a: Gradient}

By classifying the gradient values of different points in the profile, we can obtain the average gradients of the continental shelf, the oceanic basin and the continental slope, respectively; then, we can identify the region of the continental slope based on the gradient difference.

\section{Criteria b: Water depth}

By classifying the water depth of different points in the profile, we can obtain the average water depth value of the continental shelf and the oceanic basin; thus, identifying the continental shelf and the oceanic basin.

\section{Criteria c: Second derivative}

The FOS point is the point with maximum change in gradient from the continental slope to the oceanic basin, which is also the extremum point of the second derivative.

\section{Criteria d: Convex feature}

Located at the turning point from the continental slope to the oceanic basin, the FOS presents a convex feature, i.e., the FOS point is also a data point with a positive second derivative value.

\section{Criteria e: Segmentation}

Given that the adjacent points before and after the FOS point are from the continental slope and the oceanic basin, respectively, we can judge preliminarily the location of the FOS according to the segmented gradient differences of the continental slope and the oceanic basin.

\section{Criteria f: Continuity}

According to the rule that points with a similar gradient are close to each other, each point in a profile will grow towards the starting point and the ending point of the profile, and record its growth distance away from them. Therefore, the point with maximum growth distance is the FOS point.

In the end, the data points that are obtained through the above seven steps, and meet the six criteria, are identified to be the FOS points. 


\section{Application examples}

\section{Typical examples to identify FOS}

In practice, given that the judgment on the location of the FOS is influenced by various factors, a variety of complex situations should be considered during program design. Figure 5(a-d) show four typical types of topographic profile of continental margin; Fig. 5(a-c) are located at the back-arc basin, while Fig. 5(d) at the spreading continental margin. Figure 5(a) is a topographic profile of the standard continental margin that comprises " continental shelfcontinental slope-oceanic basin", from which it is easy to judge its characteristics. Point $\mathrm{A}$ is the boundary point between the continental shelf and the continental slope, whereas point $\mathrm{B}$ is the dividing point of the continental slope and the oceanic basin, namely the FOS. Figure 5(b) also has the topographic features of " continental shelf-continental slope-oceanic basin"; however, its continental slope is extremely complex, affected by submarine canyon cutting and tectonic movement, and is fragmented with convex and concave local topography developing. Thus, the identification of the FOS is vulnerable to the influence of local topography; e.g., points B and $\mathrm{D}$ in this figure could easily be misinterpreted as the FOS by the program. Therefore, we should consider the entire form of the topographic profile to avoid the interference of the local topography by eliminating the concave points. Figure 5(c) shows the influence of the oceanic-basin-margin seamount on the determination of the FOS. If we only consider the transition characteristics of topography for locating the FOS, then point $\mathrm{C}$ is easily misinterpreted as the FOS because both its gradient and second derivative are plotted in the high-value area. Therefore, we should also judge from the overall features of the profile and eliminate the interference through the characteristics of curve segmentation and continuity. Figure 5(d) shows a situation when the wide continental slope is overlapped by sea hills. The natural extension of the continental slope towards the oceanic basin is blocked by the relatively low sea hills overlapping onto the outer edge of the continental slope. Thus, point B could easily be misinterpreted as the FOS. However, analyzing of the entire profile, it can be determined that point D is a reasonable location for the FOS, because the submarine topography towards the oceanic basin changes from steep to flat, which agrees with the characteristics of the turning point from the continental slope to the oceanic basin. Here, we can also exclude the interference from local topography on determination of the FOS by eliminating concave points. In summary, the automatic identification of the integral feature of topography profile is the basis of accurate FOS determination, which requires the software program to recognize automatically the features and categories of each data point in the profile.

\section{Application for identifying FOSs}

According to Article 76 of UNCLOS and relevant technical standards and requirements by CLCS, two steps are proposed to determine the FOS.
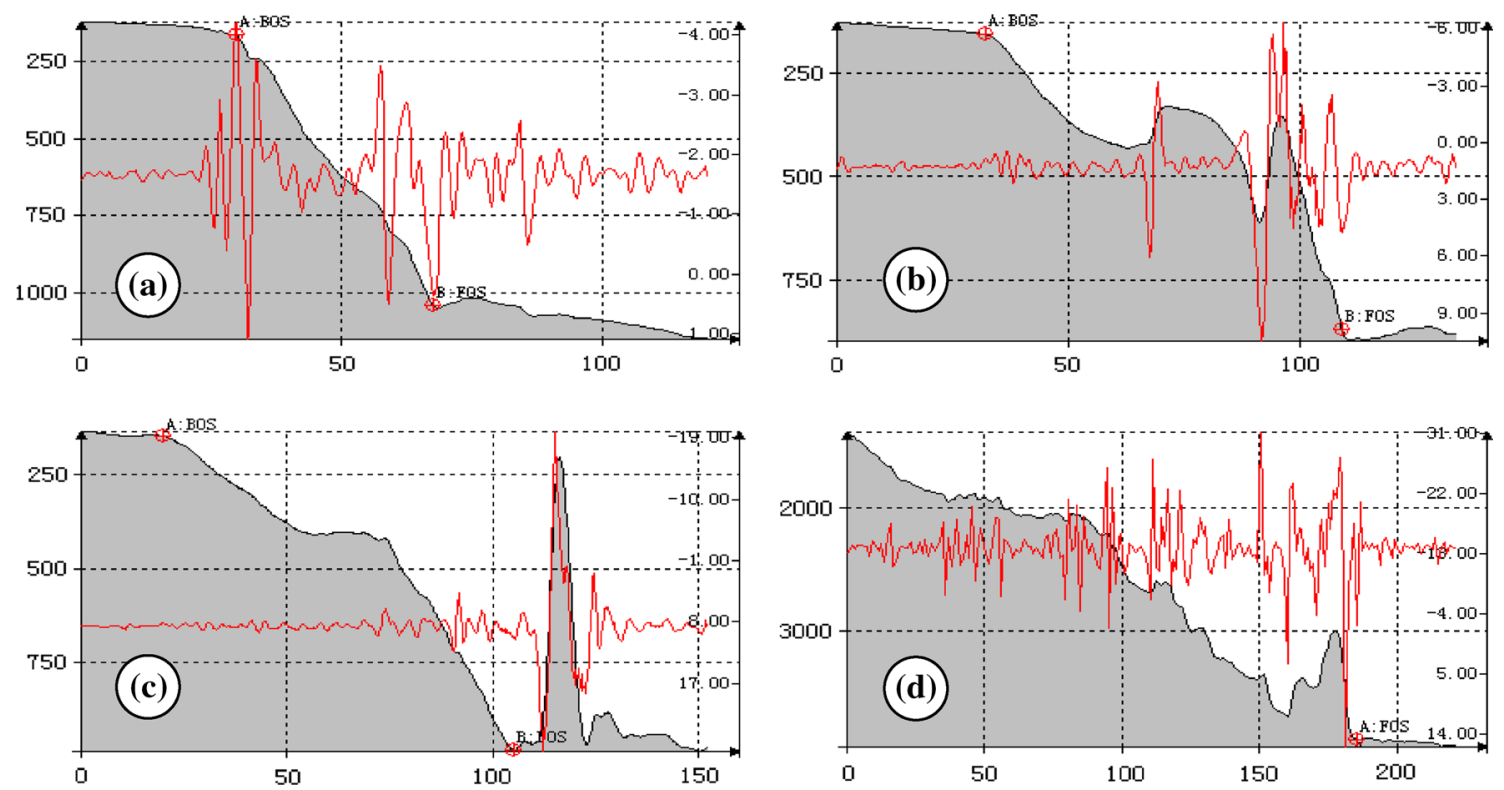

Fig. 5 Analysis of typical profiles (the black curve is the topographic profile; the red curve is the second derivative profile; FOS the foot of the continental slope) 
Fig. 6 Application example of FOS determination

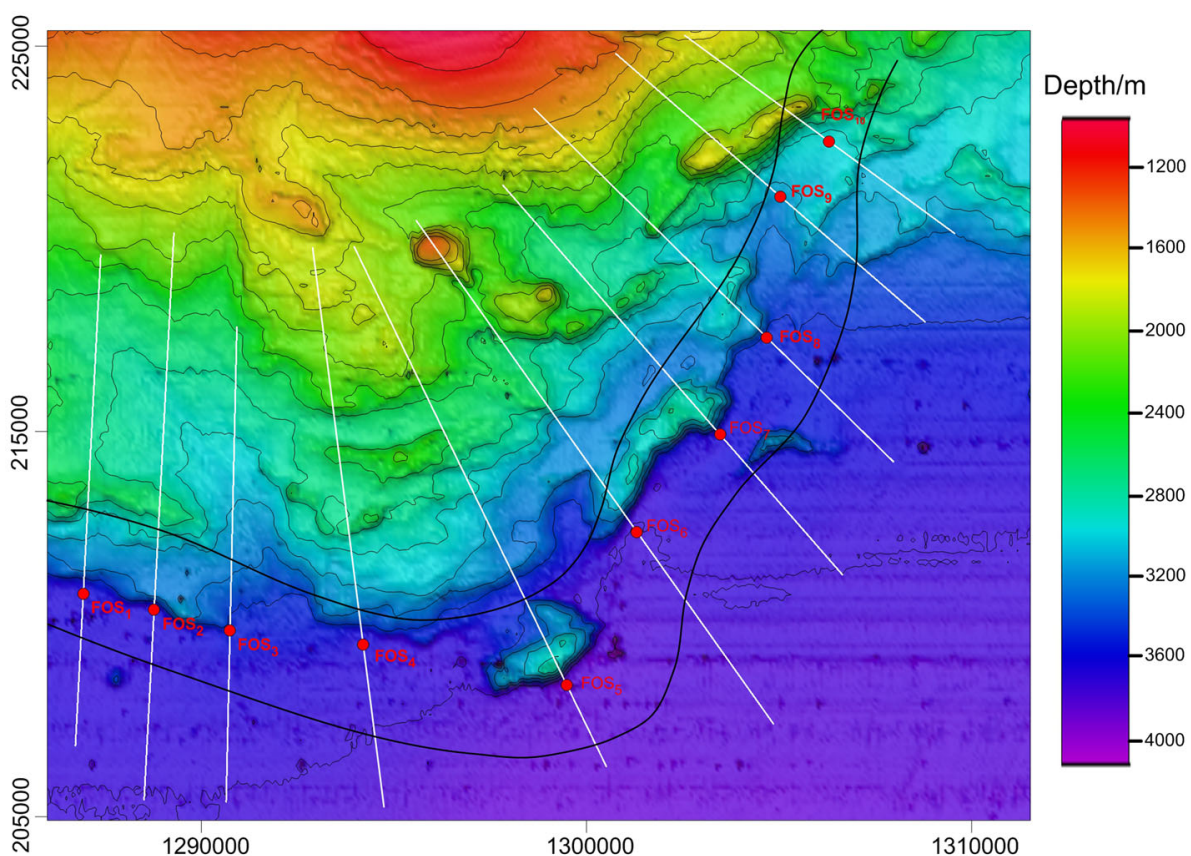

First, in a study area, we constructed its DDM with 200-m resolution based on the multi-beam echo sounding data, and formed the gradient grid and the second derivative grid. A large clinoform region is shown in Fig. 6, which is a typical continental slope: an oceanic basin topographic transition zone according to the isobaths, where water depth increases gradually from the northwest to the southeast in the range of 1500-3900 m. Based on the gradient analysis, this region is quite rugged, exhibiting a significant gradient change in submarine topography, while the overall characteristics of the gradient change agree with submarine topography, where the large gradient area corresponds to the local rugged topography. In the second derivative grid, the overall characteristics are similar to those of the gradient grid, but with a gentler trend. Additionally, the position of the peak identified by the second derivative grid is different from that of the gradient grid, i.e., the latter corresponds to the topography with maximum change, while the former corresponds to the region with maximum change in gradient-this is where the FOS is located. After stacking different layers and comprehensively analyzing water depth, topography, gradient, second derivative and other relevant information, the continental slope base region is determined.

Second, we built $10 \mathrm{NW-SE-extending} \mathrm{original} \mathrm{topo-}$ graphic profiles vertical to the strike direction of the continental slope (Fig. 6), and identified the location of all 10 FOS points (FOS $1-F O S_{10}$ in Fig. 6) through the integrated analysis method of the topography, the gradient, the second derivative, and the D-P profiles, as discussed in "Automatic identification of the FOS based on an integrated analysis of topography, slope and second derivative profiles (TSDPIA)" section. These FOS points are all located in the base region of the continental slope and the turning point from the lower continental slope to the oceanic basin; hence, they are the reasonable locations for the FOS points. To verify the validity of the program, we processed the same data and topographic profiles with a commercial software package and obtained consistent results.

In addition, in the application examples, we also used a series of DDMs with different resolutions (200, 400, 600, and $800 \mathrm{~m}$ ) to verify our algorithm. The designed algorithm shows robust performance, which can identify accurately the FOS under different resolutions of DDM, under the circumstance that seabed topographic features are not affected by the DDM.

\section{Conclusions}

This paper introduces the history of UNCLOS regarding the continental shelf, the similarities and differences of various continental shelf definitions, and determines qualitatively the FOS location for different types of continental margins. It roposes the integrated analysis method by overlapping the topographic profile, the gradient profile and the second derivative profile, to determine the base region of the continental slope, which indicates the location of the FOS.

The paper outlines the technical method and detailed procedures for identifying automatically the FOS points based on TSDPIA. Relying on the topographic profile, the 
gradient profile and the second derivative profile, the extremum points of the second derivative and the secondfitting profile applying the D-P algorithm are obtained, and then the second derivative of the original profile and the D$\mathrm{P}$ profile are calculated. Through the seven steps, four sets of increasingly succinct profile data sets have been collected, and through the comprehensive analysis of multiple factors, including the water depth, the gradient and the second derivative value of a topographic profile, as well as the concave and convex, segmentation and continuity characteristics of a curve, the automatic identification of the FOS has been achieved.

Acknowledgments The authors thank Prof. Yongqi Chen of the Hong Kong Polytechnic University for the constructive comments and polishing the English of the text. This work was supported by the Public Science and Technology Research Funds Project of Ocean 201105001), the Fundamental Project of Science and Technology (2013FY112900) and the National Natural Sciences Foundation of China (41476049).

Open Access This article is distributed under the terms of the Creative Commons Attribution 4.0 International License (http://crea tivecommons.org/licenses/by/4.0/), which permits unrestricted use, distribution, and reproduction in any medium, provided you give appropriate credit to the original author(s) and the source, provide a link to the Creative Commons license, and indicate if changes were made.

\section{References}

Alcock MB, Colwell JB, Stagg HM (2003) A systematic approach to the identification of the foot of the continental slope-article 76, UNCLOS. ABLOS '03

Antunes NSM, Pimentel FM (2003) Reflecting on the legal-technical interface of article 76 of the LOSC: tentative thoughts on practical implementation. In: Third International Hydrographic Organization (IHO) and the International Association of Geodesy (IAG) Advisory Board on the Law of the Sea (ABLOS) Conference, Monaco, pp 28-30

Bennett J (1998) Mapping the foot of the continental slope with spline-smoothed data using the second derivative in the gradient direction, US Department of the Interior, Minerals Management Service, OCS Report: MMS 97-0018

Carleton C (2006) Article 76 of the UN convention on the law of the Sea-implementation problems from the technical perspective. Int J Mar Coast Law 21(3):287-308

Collier PA, Murphy BA, Mitchell DJ, Leahy FJ (2002) The automated delimitation of maritime boundaries-an australian perspective. Int Hydrogr Rev 3(1):1-13
Douglas D-H, Peucker TK (1973) Algorithms for the reduction of the number of points required to represent a digitized line or its caricature. Can Cartogr 10(2):112-122

Gao J (2012) The seafloor high issue in article 76 of the LOS convention: some views from the perspective of legal interpretation. Ocean Dev Int Law 43(2):119-145

Hedberg H-D (1976) Ocean boundaries and petroleum resources. Science 191:1009-1018

Jakobsson M, Mayer L, Armstrong A (2003) Analysis of data relevant to establishing outer limits of a continental shelf under law of the sea article 76. Int Hydrogr Rev 4(1):2-18

Jun P (2014) Delimitation of the Continental Shelf beyond 200 Nautical Miles in the East China Sea (Chinese). China Oceans L Rev 94:124-141

Kaye S (2015) Australian practice in respect of the continental shelf beyond 200 nautical miles. Mar Policy 51:339-346

Li Q, Dehler S (2012) Identify foot of continental slope by singular spectrum and fractal singularity analysis. Geophys Res Abstr 14:6079

Magnússon BM (2014) The rejection of a theoretical beauty: the foot of the continental slope in maritime boundary delimitations beyond 200 nautical miles. Ocean Dev Int Law 45(1):41-52

Mugaas JO (2013) The effects of using different algorithms for calculating the foot of slope based on the maximum change of gradient. http://www.gmat.unsw.edu.au/ablos/ABLOS05Folder/ MugaasPaper.pdf

Ou Z-Q, Vaníček P (1996) Automatic tracing of the foot of the continental slope. Mar Geodesy 19(2):181-195

Peter J-C, Carleton C (2000) Continental shelf limits, the scientific and legal interface. Oxford University Press, Oxford

Qiu W, Jin X, Schofield C, Li M (2013) Preliminary considerations on the potential influence of submarine fans on marine delimitation. Acta Oceanol Sin 32(12):133-142

Reichert C (2009) Determination of the outer continental shelf limits and the role of the commission on the limits of the continental shelf. Int J Mar Coast Law 24(2):387-399

United Nations (1983) UNCLOS, New York

United Nations (1993) The law of the Sea: definition of the continental shelf, New York

United Nations (1999) Scientific and technical guidelines of the commission on the limits of the continental shelf. United Nations Documents, CLCS/11

United Nations (2013). http://www.un.org/Depts/los/clcs_new/submis sions_files/rus01/ RUS_page1_Arctic.pdf

Vaníček P, Wells DE, Hou T (1994) Determination of the foot of the contract report, geological survey of Canada, Atlantic Geoscience Centre, Oceanography, Dartmouth, N. S. B3A 4A2, SSC\#OSC93-3-R207/01-OSC

Verhoef J, Mosher D, Forbes S (2011) Defining Canada's extended continental shelves. Geosci Can 38(2):85-96

Wu Z, Li J, Jin X, Shang J, Li S, Jin X (2014) Distribution, features, and influence factors of the submarine topographic boundaries of the Okinawa Trough. Sci China Earth Sci 57(8):1885-1896 